\title{
PLANO DIRETOR E OS INSTRUMENTOS DE PROMOÇÃO DE INTERESSE SOCIAL: O CASO DO MUNICÍPIO DE CURRAIS NOVOS-RN
}

\author{
K. D. B. CRUZ, F. F. LIMA, P. J. S. DANTAS \\ Universidade Federal do Rio Grande Do Norte \\ karladay_cn@hotmail.com
}

Artigo submetido em 31/07/2015 e aceito em 24/06/2019

DOI: $10.15628 /$ holos.2019.3275

\section{RESUMO}

O desenvolvimento urbano das cidades brasileiras aconteceu de forma desordenada trazendo um aumento no número de pessoas e desorganização nos centros urbanos, e assim começaram a surgir problemas sociais como a ausência de moradia, a falta de infraestrutura e ineficiência de aparelhos comunitários de modo geral. É então nesse momento que o princípio constitucional da função social da propriedade urbana, ganha importância para o desenvolvimento do Brasil. Em função disso, o Poder Legislativo esforçou-se para regulamentar os instrumentos constitucionais de efetivação da função social da propriedade urbana, contemplados pela Constituição Federal, que tratam, respectivamente, do parcelamento ou edificação compulsórios, imposto predial e territorial urbano progressivo no tempo e desapropriação com pagamento em títulos da dívida pública. O estudo surgiu com o problema de pesquisa de como os instrumentos de interesse social existentes no Estatuto da Cidade têm contribuído para o cumprimento da função social da propriedade urbana, impedindo a existência de imóveis inutilizados ou subutilizados no município de Currais Novos-RN, sendo assim, o objetivo geral foi identificar de que forma esses instrumentos tem contribuído para o cumprimento da função social. As teorias estudadas foram a Constituição Federal, o Estatuto da Cidade, e o Plano Diretor do município de Currais Novos, Lei complementar no. 08 de 1 으 de novembro de 2007, e a metodologia aplicada aconteceu por meio de entrevistas e questionários com dois secretários do município e três servidores. Por fim, conseguiu-se obter resultados que ajudaram a entender os instrumentos constitucionais como também, o objetivo da função social da propriedade urbana para o desenvolvimento social.

PALAVRAS-CHAVE: Plano Diretor, IPTU, Função Social da propriedade urbana, Parcelamento e Desapropriação do solo.

\section{DIRECTOR PLAN AND THE INSTRUMENTS OF SOCIAL PROMOTION OF INTEREST: THE CASE OF CURRAIS NOVOS-RN CITY}

\begin{abstract}
The urban development of cities in Brazil happened haphazardly, bringing an increase in the number of people and disruption in urban centers, and thus began to occur problems such as lack of housing, lack of infrastructure and inefficient community appliances in general. It is at this point that the constitutional principle of the urban property social function gets importance for the development of Brazil. According to that, the Legislature has making efforts to regulate the constitutional instruments of effecting social function of urban property covered by the Federal Constitution, which deal respectively with the compulsory subdivision or construction, progressive property and urban land tax in time with payment in government bonds. The study came up with the problem of research about how the existing instruments of social status in the City have
\end{abstract}

contributed to the fulfillment of the social function of urban property, preventing the existence of unused or underused buildings in the Currais Novos-RN city, so that the general objective was to identify how these instruments has contributed to the fulfillment of social function. The theories studied were the Federal Constitution, the Statute of the City, and the Master Plan of Currais Novos city, the Complementary Law no. 08, from November 1, 200. The methodology applied happened through interviews and questionnaires with two county secretaries and three servers. Finally, we were able to obtain results that helped to understand the constitutional instruments as well, the aim of the social function of urban property for social development.

KEYWORDS: Master Plan, Property tax, Urban property social function, Compulsory subdivision or construction, Payment in government bonds. 


\section{INTRODUÇÃO}

Com o início do processo de industrialização ocorrido no Brasil na década de 30 do século XX e consequentemente com a intensificação do êxodo rural, surgiram várias problemáticas que ainda persistem nos centros urbanos. A organização e ocupação do espaço urbano é tema constante que se apresenta como uma das várias questões que a sociedade contemporânea tem a responder de formar eficaz. Tentando criar condições de sobrevivência nas cidades, com dignidade e qualidade de vida, consagrou-se em nosso país a função social da propriedade urbana que atualmente é princípio constitucional.

Diante disso, o Plano Diretor Municipal assume papel relevante na política de desenvolvimento social dos centros urbanos com a finalidade de proporcionar bem estar e qualidade de vida nas cidades. É um instrumento legal que promove o desenvolvimento econômico e social nos municípios.

Nas cidades, diariamente encontramos problemas que afetam à população como: conflitos sociais, econômicos e culturais. A forma de melhor lidar com essas situações é a elaboração de um Plano Diretor, o que possibilita um planejamento conjunto da cidade e a utilização de instrumentos de intervenção urbana, ajudando na efetiva realização da função social da propriedade urbana na cidade.

O Plano Diretor Municipal assume papel relevante na política de desenvolvimento social dos centros urbanos com a finalidade de proporcionar bem estar e qualidade de vida nas cidades. Conforme consta no art. 182, § 4, da Constituição Federal 1988 é facultado ao Poder Público Municipal exigir, mediante lei incluída no Plano Diretor, o adequado aproveitamento do solo urbano não edificado, subutilizado e não utilizado pelo proprietário do imóvel. Dentre as penalidades que pode ser imposta aos proprietários é o parcelamento ou edificação compulsórios, o IPTU progressivo no tempo e a desapropriação com pagamento em títulos da dívida pública que estão descritas no Estatuto da Cidade.

Tais sanções são atos de política fiscal que é dotado de finalidade social. Por meio de maior ou menor imposição tributária há um desestímulo para proliferação de áreas não edificadas, subutilizadas ou não utilizadas no espaço urbano. O Plano Diretor Municipal por meio de desses instrumentos de promoção social, tem sido utilizado com o intuito de promover o desenvolvimento e crescimento das cidades proporcionando o uso adequado do espaço urbano cumprindo a propriedade sua função social.

Conforme a necessidade da utilização de forma correta dos imóveis inutilizados e subutilizados surge um questionamento: como os instrumentos de interesse social existentes no Estatuto da Cidade têm contribuído para o cumprimento da função social da propriedade urbana, impedindo a existência de imóveis inutilizados ou subutilizados no município de Currais Novos-RN? Desta forma o objetivo da pesquisa era identificar de que forma os instrumentos de promoção de interesse social no município de Currais Novos-RN tem contribuído para o cumprimento da função social da propriedade urbana. 
O estudo em questão justificou-se em conhecer como os instrumentos de interesse social existentes no Estatuto da Cidade têm sido utilizados pelo município de Currais Novos-RN, como também, entender o uso da função social da propriedade urbana. Este trabalho teve a oportunidade de compreender a forma como os imóveis inutilizados ou subutilizados estão sendo tratados no município e é relevante para a sociedade já que o interesse na função social deve cumprir a coletividade.

\section{ASPECTOS DO PLANO DIRETOR}

\subsection{Plano Diretor}

Na perspectiva do município, o Plano Diretor em consonância com o Estatuto da Cidade surge como instrumento hábil da política de urbanização, tendo em vista o bem estar da população e o alcance da qualidade de vida nas cidades. Nas palavras de Silva, C.H.D. $(2008$, p. 7) "o plano diretor é o instrumento básico da política de desenvolvimento e de expansão urbana. [...] dispõe sobre a política urbana do município, organizando o funcionamento e o crescimento da cidade".

A Constituição da República depreende-se que o Plano Diretor Municipal é o instrumento legal para o atingimento do pleno desenvolvimento das funções sociais da cidade, bem como visa garantir o bem-estar dos munícipes. Deve ser aprovado por lei pela Câmara Municipal, e é obrigatório para cidades com mais de vinte mil habitantes. Significa dizer, que cidade com menos de vinte mil habitantes podem elaborá-lo de forma facultativa. Ele deve seguir, contudo, as linhas gerais de planejamento urbano contidas no Estatuto da Cidade, aprovado pela Lei Federal 10.257/01, e que regulamenta os Artigos 182 e 183 da Constituição Federal.

A aprovação dessa lei repercutiu sobremaneira em todo o país, tendo em vista que a partir dessa regulamentação, os municípios - com mais de vinte mil habitantes - estavam, necessariamente, obrigados a elaborar um Plano Diretor ou adequar o já existente à sua matriz legal. A ideia trabalhada pelo Estatuto da Cidade é o da cidade ilegal que se caracteriza como sendo a parcela do município que está desprovida de infraestrutura e de que qualquer benefício que o resto da cidade possui, e quase sempre está localizada em áreas ambientalmente frágeis, onde o risco de enchentes e deslizamentos são constantes (TOMAS, 2005).

No dia 01 de Novembro de 2007, por meio da Lei Complementar Municipal º 08 o município de Currais Novos-RN, cumprindo as determinações contidas na Constituição Federal, promulgou o Plano Diretor Participativo do município. Trata-se de uma lei que tem como intenção ser o instrumento global e estratégico da política de desenvolvimento urbano e rural, determinante para todos os agentes públicos e privados que atuam no município.

Entre as diversas ações e diretrizes propostas no referido plano diretor, cabe destacar o que está contido no Artigo $2^{\circ}, \S 2^{\circ}$ da Lei Complementar $\mathrm{N}^{\circ} 08$, que, em consonância com o Estatuto da Cidade preceitua que:

Art. $2^{\circ}-[\ldots]$ o processo de planejamento municipal compreende, nos termos do artigo $4^{\circ}$ da Lei Federal $n^{\circ} 10.257$, de 10 de julho de 2001 - Estatuto da Cidade, os seguintes itens: 


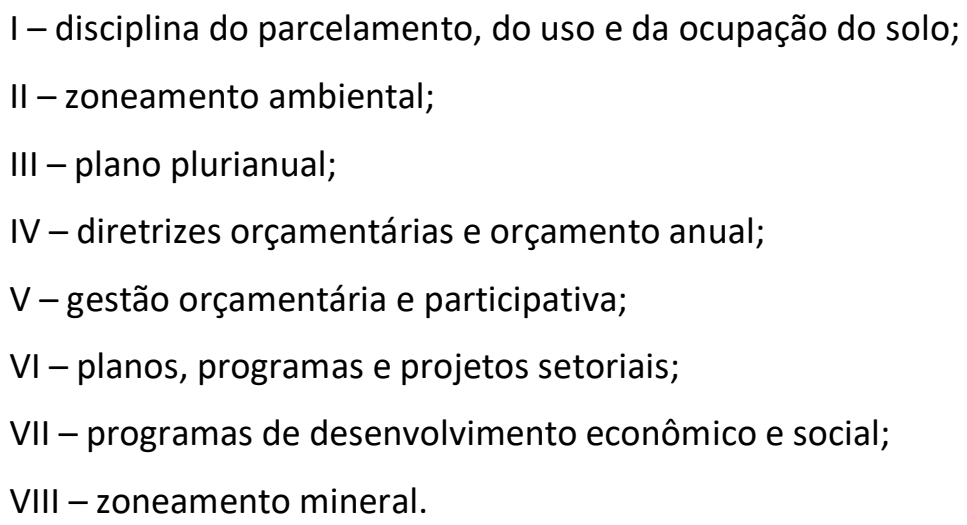

Além dessas determinações, o Artigo $3^{\circ}$ ordena que o Plano Diretor abrange a totalidade do território do município, definindo: a política de desenvolvimento urbano do município; a função social da propriedade urbana e rural; as políticas públicas do Município; o plano urbanísticoambiental; e a gestão democrática.

Percebe-se a intenção do legislador em discorrer sobre as problemáticas trazidas pelo Estatuto da Cidade, pensando no planejamento urbano como um todo, definindo políticas de urbanização e de uso e ocupação do solo urbano e rural, bem como a definição do que, para o município, é o conceito de função social da propriedade urbana.

\subsection{Função Social da Propriedade Urbana}

Uma característica bastante pertinente é evidenciada pela Constituição em relação à propriedade urbana, é o da função social. É compreendido, que o conceito de propriedade passa por um novo significado. A propriedade urbana, dentre outros direitos, possui garantia de sua inviolabilidade estabelecida pelo Art. $5^{\circ}$ da Carta Magna ${ }^{1}$.

Mas apesar de ser inviolável, a propriedade deve atingir um objetivo, o da função social. Vale dizer que a Constituição Federal apregoa que a propriedade tem que "[...] gerar, com a ajuda do mercado, da sociedade e do Estado: trabalho, emprego, renda e bem-estar econômico, financeiro e social" (SILVA, C.H.D., 2008, p. 36). No mesmo sentido vem o pensamento de Sant'ana (2006, p. 133) quando assevera que o plano diretor deve buscar "[...] o desenvolvimento econômico, social e administrativo, bem como o desenvolvimento físico do território municipal".

Uma característica bastante pertinente é evidenciada pela Constituição em relação à propriedade urbana, é o da função social. É compreendido, que o conceito de propriedade passa por um novo significado. O conceito da função social da propriedade urbana é subsidiário do conceito de função social da propriedade, e teve um novo ordenamento jurídico visando atender não só as mudanças nas relações sociais de produção e distribuição das riquezas e bens, mas também as novas características dos valores sociais (SILVA, C.H.D., 2008). Cada município, mediante o Plano Diretor, definirá o que para ele significa função social da propriedade urbana. Portanto,

\footnotetext{
${ }^{1} \mathrm{O}$ Art. $5^{\circ}$ da CF possui status de Cláusula Pétrea, não podendo ser revogado ou modificado, nem mesmo por Emenda Constitucional.
} 
função social da propriedade urbana remete a ideia de que o bem-estar coletivo e a qualidade de vida deve se dar de forma sustentável, mediante a existência de infraestrutura básica urbana.

\subsection{Parcelamento ou Edificação Compulsórios}

O parcelamento do solo é instrumento indutor de urbanização, aplica-se de formar espontânea pelo proprietário da terra, o processo acontece com um planejamento do parcelamento da terra em lotes e seguindo para aprovação da prefeitura, e depois no registro de imóveis. Este instrumento transfere ao domínio público as ruas e áreas ao uso público. Passado essas etapas a edificação e futura utilização darão cumprimento à função social da propriedade (SANT'ANA, 2006).

O art. 77 do Plano Diretor de Currais Novos estabelece que os titulares dos imóveis inseridos nas situações de parcelamento, edificação ou a utilização compulsória dos imóveis não edificados serão notificados pelo Poder Público Municipal, na forma prevista do art. 5 do Estatuto da Cidade.

Bueno apud Sant'ana (2006, p. 98) informa:

Com a edição do Estatuto da Cidade o atendimento da norma constitucional é feito da seguinte forma: lei municipal específica para área incluída no plano diretor determina ao proprietário que dê adequada utilização a sua propriedade urbana. O papel da 'lei municipal específica' é estabelecer as condições e os prazos para implementação da obrigação de fazer. O proprietário de área nestas condições é notificado para que ele próprio parcele, edifique ou utilize o solo urbano não edificado, subutilizado ou não utilizado. E, no caso de desatendimento da obrigação, o proprietário está sujeito ao IPTU progressivo no tempo e, após certo lapso de tempo, a desapropriação.

O Estatuto da Cidade em seu artigo 42, I, explana que a obrigação de parcelar ou edificar só pode ser estabelecida em áreas dotadas de infraestrutura ociosa e para as quais haja demanda no mercado imobiliário. Sant'ana (2006) relata que a finalidade do parcelamento, edificação ou utilização compulsória é combater a retenção de glebas e lotes não edificados, que tenham infraestrutura e serviços urbanos, reduzindo custos na urbanização e aumentando em investimentos públicos, além de estimular o uso da propriedade urbana conforme a função social de cada município.

\subsection{IPTU Progressivo no Tempo}

O imposto sobre a propriedade predial e territorial urbana é um tributo de competência exclusiva dos municípios e do Distrito Federal, tendo como fundamento o Art. 156, I da Constituição Federal. É um imposto unicamente arrecadador, e como tal, não exige contrapartida por parte dos municípios e não é vinculado a nenhuma atuação do Estado. Além disso, o Artigo 156, §1 da Constituição Federal determina que o IPTU poderá ser progressivo em razão do valor do imóvel, além de poder ter alíquotas de acordo com a localização e o uso do imóvel.

Em outras palavras, o IPTU pode ser objeto tanto de políticas fiscais como extrafiscais (SANT'ANA, 2006). A natureza extrafiscal do IPTU progressivo não tem a finalidade de arrecadação de mais tributos, mas objetiva que o proprietário do imóvel destine a propriedade para o cumprimento da sua função social e não promova a especulação imobiliária. 
No entanto, a Constituição Federal, e, por conseguinte, o Estatuto da Cidade, atribuíram ao IPTU outra função: de poder ser utilizado como instrumento municipal para obrigar os proprietários de imóveis a efetuarem o adequado aproveitamento das áreas não edificadas, subutilizadas ou não utilizadas. Nesse sentido ele pode ser progressivo no tempo, o que quer dizer ter alíquotas progressivas, maiores a cada ano. De acordo com Rocha (2008, p. 156):

A ideia [sic] aqui estabelecida pela Constituição é a de um mecanismo a ser regulado pela lei em que as alíquotas, ano a ano, tornam-se maiores sobre aqueles imóveis urbanos que são inutilizados ou subutilizados, estimulando, assim, o adequado aproveitamento do solo urbano.

Além disso, o Artigo 156, $\$ 1$ da Constituição Federal² determina que o IPTU poderá ser progressivo em razão do valor do imóvel, além de poder ter alíquotas de acordo com a localização e o uso do imóvel. Em outras palavras, o IPTU pode ser objeto tanto de políticas fiscais como extrafiscais (SANT'ANA, 2006). Para que seja estabelecida a progressividade da alíquota do IPTU fazse necessário os instrumentos que seguem abaixo:

- Plano Diretor;

- Lei municipal específica para a área incluída no plano diretor;

- Existência de notificação ao particular, a qual conste prazos e condições ao particular para que cumpra as obrigações da lei municipal específica;

- Descumprimento das obrigações pelo particular.

A competência para fixar os percentuais das alíquotas é do município, o qual deve observar as restrições impostas pela Lei 10.257/2001.

\subsection{Desapropriação com Pagamento em Títulos da Dívida Pública}

A desapropriação permite ao poder público a transferência de forma compulsória da propriedade privada para o domínio público, sendo por utilidade, necessidade pública ou interesse social (SANT'ANA, 2006). O Estado determina a perda do direito de posse sobre um bem, passando a propriedade para o patrimônio do Estado.

Esse procedimento passa pelo ato administrativo que inicia com a declaração de utilidade ou de interesse social dos imóveis atingidos, sendo então avaliados para a devida indenização em dinheiro, conforme apresenta o art. 5o da Constituição Federal, no entanto, existe conflito no pagamento, já que o Estatuto estabelece que o Poder Municipal tem o direito de desapropriar o imóvel e que o pagamento poderá ser em títulos da dívida pública (SILVA, 2009).

O Estatuto da Cidade explana que embora não se possa negar o caráter penal deste instrumento urbanístico de promoção social, o fato é que não se trata de um ato meramente

\footnotetext{
${ }^{2}$ Com redação dada pela Emenda Constitucional $n^{\circ} 29$, de 2000.
} 
punitivo, mas antes um ato de adequação do imóvel a função social da propriedade (SANT'ANA, 2006).

Ainda conforme Sant'ana (2006, p. 111):

(...) além de prever as regras de desapropriação, estabelece as obrigações, dela decorrentes, do Município, que deverá proceder ao adequado aproveitamento do imóvel no prazo de cinco anos: o Poder Público assume, através da desapropriação, a responsabilidade e a obrigação que atingira o proprietário em face da especial característica da área, decorrente da indicação para parcelamento, edificação ou utilização compulsória. E mais, para o cumprimento desta obrigação, a lei federal autoriza a municipalidade a alienar ou conceder o imóvel á terceiro, transferindo-se a este a obrigação inicial.

Compreende-se que desapropriação é para fins de reforma urbana, e a obrigação se transfere ao município ou a terceiro, e só se torna efetivo o cumprimento da função social como o cumprimento da obrigação, por meio das obras concluídas. Fica confirmado o fato que a desapropriação só será tomada depois de adotadas o parcelamento ou edificação compulsória e tributação do imposto territorial ou predial progressiva no tempo.

Existe dificuldade para a realização deste instrumento de política urbana, já que o pagamento será efetuado por títulos da dívida pública, tendo a aprovação do Senado Federal, e assim retira do município a decisão sobre a efetivação das desapropriações (SANT'ANA, 2006). No Plano Diretor do município de Currais Novos, Lei complementar no. 08 de 1ㅇ de novembro de 2007, no artigo 80 define "não se aplica pelo município, a desapropriação de imóveis mediante pagamento com títulos da dívida pública." Sendo assim, o município aplica outros instrumentos de promoção social para cumprir com sua função social.

Por fim, vale ressaltar que como argumenta a Lei Federal № 10.257/2001 a desapropriação é um instrumento urbanístico que dar a oportunidade do Poder Público aplicar uma sanção ao proprietário de imóvel urbano, por não respeitar o princípio da função social da propriedade urbana (BRASIL, 2001).

\section{METODOLOGIA DO ESTUDO}

O presente estudo propôs-se a investigar, em profundidade, como o IPTU progressivo no tempo e os instrumentos de promoção social têm contribuído para o cumprimento da função social da propriedade urbana, impedindo a existência de imóveis inutilizados ou subutilizados no município de Currais Novos-RN. Neste sentido, o município de Currais Novos-RN constitui-se o local (comunidade) em que a situação/problema ocorre. Na Figura 1 será possível observar sua localização no estado do Rio Grande do Norte, a qual faz parte da microrregião do Seridó oriental. 


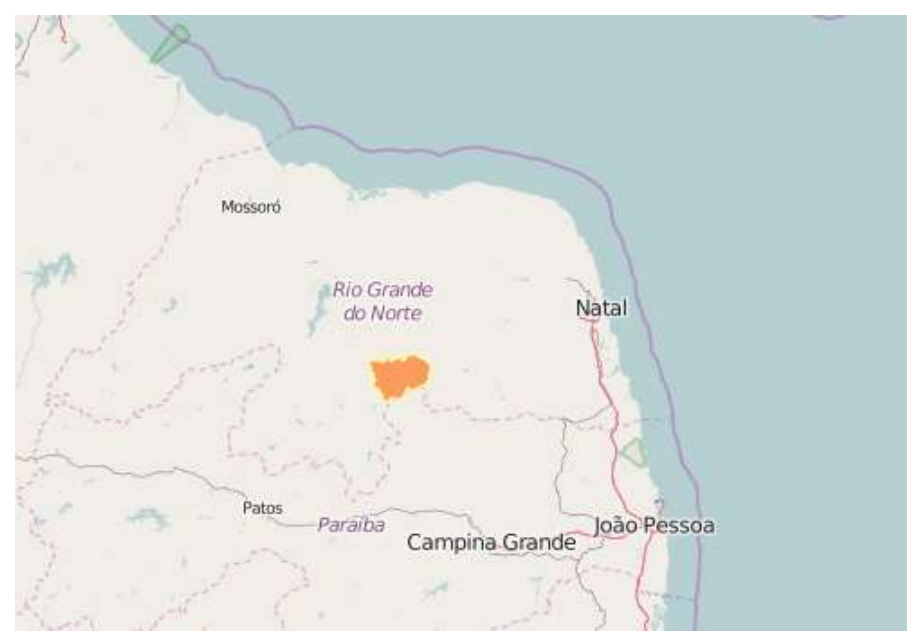

Figura 1: Localização do município de Currais Novos/RN.

O mapa do IBGE apresentado na Figura 1 é o município de Currais Novos que de acordo com o IBGE tem uma população estimada para 2015 de 44.887 habitantes. A tabela 1 relata o crescimento populacional nos últimos 15 anos de acordo com o Censo demográfico de 2000, contagem populacional de 2007, e Censo de 2010.

Tabela 1: Crescimento populacional do município.

\begin{tabular}{l|l}
\hline Ano & Currais Novos \\
\hline 2000 & 40.791 \\
\hline 2007 & 42.066 \\
\hline 2010 & 42.652 \\
\hline 2015 & 44.887 \\
\hline
\end{tabular}

O município teve crescimento populacional e desenvolvimento apesar das dificuldades da seca dos últimos tempos. O índice de desenvolvimento humano municipal - IDHM em 2000 foi 0,572 e 2010 aumentou para 0,691 ficando na média nacional. Sua população com moradia na zona urbana foi $88,6 \%$ em 2010, tendo mais de 11.181 domicílios particulares permanentes, sendo $89,7 \%$ com saneamento básico adequado (IBGE, 2010).

Quanto aos meios, a investigação é caracterizada como um estudo do caso, com uma abordagem qualitativa. A escolha dos atores da pesquisa foi intencional, identificados cinco agentes públicos - dois secretários municipais e três funcionários concursados da prefeitura - que trabalham nos setores relacionados ao tema da pesquisa: Secretaria Municipal de Finanças e Planejamento, Secretaria Municipal de Infraestrutura e Serviços Urbanos e Secretaria Municipal de Agricultura e Meio Ambiente. Para efeito dessa pesquisa, os cinco entrevistados foram denominados de "atores", e, optou-se por mencioná-los como A1, A2, A3, A4 e A5 na análise dos dados.

A análise foi realizada tendo como base o referencial teórico acerca dos temas. Por conseguinte, a análise levou em consideração esses instrumentos no sentido do cumprimento da 
função social da propriedade urbana, bem como na integral aplicabilidade do Plano Diretor. Por fim, a observação da situação/problema no contexto em que os fenômenos acontecem, permitiu ainda, comparar, contrapor, e/ou concordar com aquilo que foi relatado pelos atores. Ainda como fonte de estudo, utilizou-se documentos e legislações municipais correlatas aos temas propostos na pesquisa.

\section{ANÁLISE DOS DADOS}

De início foi perguntado aos entrevistados se a prefeitura municipal de Currais Novos-RN possui algum mapeamento da zona urbana onde seja possível identificar os imóveis não edificados, subutilizados ou inutilizados. As respostas foram unânimes no sentido de que não existe nenhum mapeamento "específico" para identificar quais propriedades urbanas não cumprem com sua função social. Só existe um mapeamento genérico da cidade bastante antigo e desatualizado, como é verificado nas respostas abaixo:

A prefeitura não possui mapa de cadastro de imóveis, a sua implantação só será possível após a conclusão do Plano Diretor. (A1)

O mapeamento é ainda muito simplificado e os dados que constam no SIAT (Sistema integrado de arrecadação tributária) da prefeitura são os dados que ainda precisam ser atualizados. (A2)

Não Existe. (A3)

[...] um mapeamento específico né?! Não. A gente trabalha com o cadastro imobiliário que realmente já faz muito tempo que não foi atualizado. (A4)

Não aparecem os imóveis abandonados, mas aparecem os povoados, aparecem as estradas, as estradas vicinais mais importantes do governo na zona rural, onde ligam os povoados. (A5)

Segundo um dos entrevistados, a ausência desse mapeamento está relacionada a uma questão meramente financeira, pois já teria previsão orçamentária para sua realização, contudo, sem condições de implantação por parte da prefeitura:

Já está previsto em orçamento municipal, tudo. Agora é uma questão que requer um certo valor financeiro significativo que a prefeitura até o momento não teve condições de fazer isso. Por que tem que contratar uma empresa de consultoria especializada na área para fazer esse recadastramento imobiliário. (A4)

Em seguida, foi verificado quanto à aplicação do Art. 77 do Plano Diretor municipal, que, a exemplo da Constituição Federal e do Estatuto das Cidades, prevê o parcelamento ou edificação compulsório de solos urbanos não edificados, subutilizados ou inutilizados. As afirmações abaixo são claras no sentido da inexistência dessa ação:

O Plano Diretor, apesar de aprovado em 2007, ainda não foi concluído. Por esse motivo ainda não foi implantado de fato. (A1) 
Já que não há mapeamento no Plano Diretor atual, então não há como aplicar este procedimento. (A3)

Na realidade não... não existe, digamos assim, um trabalho regular disso aí. (A4)

Nós não temos nenhum procedimento sobre isso, hoje. A prefeitura não toma nenhuma providência. Hoje você vê imóveis, terrenos grandes, em áreas nobres, ... em áreas boas de Currais Novos que tem terrenos que faz 200 anos que tem lá: a prefeitura não toma nenhuma providência. (A5)

Ficou evidente que a prefeitura não notifica os proprietários de imóveis. Pelo porte da cidade, é possível, mesmo sem possuir dados específicos sobre determinado fato, ter conhecimento da realidade. Um dado novo é apresentado por A2, que discorre sobre uma lei municipal específica para tratar da questão do parcelamento do solo. Entretanto, mesmo existindo essa lei, fica evidente que nenhuma notificação é realizada pela Administração do município, só existindo a previsão legal, vejamos:

Há uma lei municipal $n^{\circ} 860$ de 03 de novembro de 1979, que trata exclusivamente do parcelamento do solo. Todos os procedimentos relativos aos seus proprietários de imóveis e notificações estão previstas nesta lei. (A2)

Em seguida, foi perguntado se a prefeitura municipal possui algum sistema de gerenciamento de dados para controlar as informações sobre parcelamento, uso do solo e edificações, que subsidiem a gestão do uso e ocupação do solo. Conforme as respostas assinaladas abaixo, a prefeitura não possui nenhum sistema de gerenciamento de dados:

Devido a não implantação do Plano Diretor, o que orienta a prefeitura nas determinações do uso e ocupação do solo do município é o código de obra do município. (A1)

Possui o SIAT (Sistema integrado de arrecadação tributária). Um programa da empresa TINUS INFORMÁTICA e gerenciado pela Secretaria Municipal de Finanças e Planejamento. (A2)

Não. Prevemos que este seja implantado com a revisão do Plano Diretor de Currais Novos. (A3)

Não, o que tem é o sistema de cadastro imobiliário. Existe esse cadastro, mas muito atrasado. Eu não sei qual foi o último ano que foi realizado isso, uma coisa antiga. Tá totalmente desatualizado. (A4) Não, não tem isso não. Nós temos o mapeamento com a localização dos imóveis. Nesse mapeamento temos o cadastro de todos os imóveis, claro, no nosso sistema de cadastro imobiliário. (A5)

Foi perguntado aos entrevistados de que forma as diretrizes norteadoras da função social da propriedade urbana tem orientado as políticas públicas por parte da prefeitura municipal:

Não há uma implantação integral dessas políticas públicas. O plano diretor foi criado em 2007 e está sendo revisado em 2011. (A2)

Veja bem! Há uma série de dificuldades. Da parte de saneamento, a prefeitura está elaborando um plano municipal de saneamento do município, certo! [...] Essa parte de mobilidade, de acessibilidade a gente não tem trabalhado sistematicamente a isso. Não existe nenhum trabalho de transporte coletivo. Já tentaram... a iniciativa privada já tentou em algumas épocas, mas pelo fato de o grande 
número de mototáxis, não é?! Fica inviável talvez alguém tentar implantar uma linha de transporte coletivo. (A4)

Transporte coletivo aqui não existe. Transporte coletivo é outra questão. Já se tentou implantar o sistema de transporte coletivo. Existe aqui uma turma... Muita gente com a questão do moto-taxista. (A5)

Analisando a fala de A4, é visível que o assunto de transporte coletivo em Currais Novos-RN, na visão da prefeitura municipal, é deixado a cargo da iniciativa privada. Complementando a análise com o que A5 afirmou, tem-se que não há intenção da prefeitura regulamentar, tendo como justificativa, a questão do grande número de moto-taxistas existente no município. Além disso, foi deixada uma dúvida por parte dos entrevistados, já que não ficou claro como a prefeitura tem buscado atingir os princípios da função social nas políticas públicas. O mais interessante é evidenciado por A2, quando diz que não houve ainda implantação integral dessas políticas públicas.

Quanto às diretrizes utilizadas na realização das políticas públicas, foi questionado quais são os parâmetros utilizados para efetuar as obras necessárias para o saneamento ambiental, à infraestrutura e serviços públicos, transporte coletivo, à mobilidade urbana e acessibilidade. Houve certa contradição nas respostas como é possível observar:

Os parâmetros são as leis do código de obras, da lei do parcelamento urbano, da lei do zoneamento, o plano diretor, os programas do ministério das cidades e as orientações advindas da secretaria municipal de obras. (A2)

Código de Obras, Código de Posturas, Leis federais e estaduais. (A3)

O que estabelece hoje o Estatuto das Cidades? Pra que se loteie um terreno o proprietário tem que dar estrutura básica necessária. Certo?! Que é no caso água, energia e esgotamento. O grande problema nosso hoje na administração municipal é a quantidade de loteamentos irregulares que existe. Então, a gente tá sempre se reunindo com a procuradoria jurídica da prefeitura pra vê as formas de inibir essa questão do loteamento irregular. As pessoas compram uma gleba de terra, aí loteiam a bel prazer, vendem. Quando a gente toma conhecimento já tá vendido, já tem inúmeros donos tipo sem documento de nada, sem licenciamento, sem escritura. (A4)

Eu acho que é a questão da população que tem lá: quantas casas construídas; e quantas pessoas moram. O parâmetro inicial é esse: saber quantas casas foram construídas e quantos moradores tem. Com isso a prefeitura vai ver a questão do esgotamento sanitário, do abastecimento d'água, essas coisas. (A5)

Analisando as respostas percebe-se que não há um alinhamento no sentido de definição sobre quais parâmetros a prefeitura usa.

Foi perguntado também, aos entrevistados se o município de Currais Novos-RN aplica o IPTU progressivo no tempo. O questionário possuía perguntas específicas em caso de resposta afirmativa ou negativa à assertiva anterior. Como as respostas foram no sentido negativo foi perguntado por que o município não aplica. Segue abaixo algumas afirmações: 
Há a necessidade de um sistema sólido de dados econômicos dos contribuintes. A solidez e fidelidade destes dados são o suporte para implantação do imposto progressivo. (A2)

O Plano Diretor tá aí, tem essa lei, mas o Plano Diretor não foi implantado na prática em Currais Novos. Está esperando implantar. Quando for implantado é que a gente vai ver algumas coisas que pode tomar. IPTU progressivo aqui eu não acho uma boa ideia. Por que é o IPTU que existem brechas jurídicas, algumas pessoas acham que é inconstitucional essa questão do IPTU progressivo. (A5)

Nessa parte da pesquisa é que ficou esclarecida a questão da aplicabilidade do Plano Diretor na prática. Ao responder essa questão, A5 assevera que o Plano Diretor não está, de fato, sendo levado em consideração. Os demais entrevistados deram respostas que apontam na mesma linha de raciocínio:

Devido a não implantação do Plano Diretor, o que orienta a prefeitura nas determinações do uso e ocupação do solo do município é o código de obra do município. (grifo nosso) (A1)

Não há uma implantação integral dessas políticas públicas. O Plano Diretor foi criado em 2007 e está sendo revisado em 2011. (A2)

Prevemos que este seja implantado com a revisão do PDCN. (A3)

Então, existe essa dificuldade da gente é... digamos assim cumprir o que ta previsto no plano diretor em função disso, esse plano não tem aplicabilidade funcional hoje no nosso sistema. (A4)

Então, o que se conclui inicialmente, é que o Plano Diretor de Currais Novos-RN só foi elaborado para fins de cumprimento de mandato Constitucional, que obriga os municípios com mais de vinte mil habitantes - sob a possibilidade de algumas penalidades - a promulgarem seus respectivos Planos Diretores. Apesar de A5 ter declarado que o Plano Diretor e, consequentemente, suas diretrizes, não estar sendo aplicado na prática, o IPTU progressivo no tempo está integralmente apto, e bem delineado em sua forma de aplicação, para que não seja utilizado.

Já que não aplica o IPTU progressivo no tempo, os atores da pesquisa foram impelidos a responder que outros instrumentos o município de Currais Novos-RN adota para o cumprimento da função social da propriedade urbana. A seguir são apresentadas as respostas de A2 e A5, já que os demais não responderam alegando não se aplicar à sua área de atuação.

As alíquotas são iguais para todos os contribuintes, mas os coeficientes são diferentes, dependendo das áreas geográficas da cidade. (A2)

Não, tem não! A prefeitura não tem hoje nenhuma providência pra esses imóveis não edificados em Currais Novos. Poderá ser criada uma lei paralela pra essa questão dos imóveis não edificados ser cobrado o IPTU progressivo no tempo - você tratar o IPTU proporcional para os imóveis edificados, e os não edificados você cobrar o IPTU progressivo - porque vai forçar os proprietários dos imóveis a construir. (A5)

Incontestavelmente a resposta proferida por A5 não poderia ser diferente, estando perfeitamente alinhada com as demais opiniões emitidas anteriormente. A resposta emitida por A2, 
discorrer única e exclusivamente acerca da aplicação de alíquotas proporcionais do IPTU, o que não configura, em nenhum momento, política de interesse coletivo.

Seguindo a linha de pesquisa, averiguou-se a respeito da desapropriação mediante pagamento em títulos da dívida pública. As respostas caminharam novamente no sentido da não aplicação, ou até mesmo, da incerteza de se, em algum momento, a prefeitura já o utilizou:

Não. (A2)

Não. Não tenho conhecimento se houve algum. Já houve algumas desapropriações. Na realidade, a prefeitura tenta evitar a questão da desapropriação, tenta negociar pra adquirir realmente no sistema de compra e venda. Mas, em períodos anteriores houve desapropriações. Mas, eu não tenho conhecimento, a forma de pagamento e como foi efetuado. (A4)

Não. Bem, nesse tempo que estou aqui, a prefeitura não fez nenhuma desapropriação. (A5)

Dando prosseguimento aos questionamentos, procurou-se investigar quais instrumentos urbanísticos a prefeitura municipal de Currais Novos-RN utiliza para estimular a requalificação de imóveis, nos sentido de prover o melhor aproveitamento da infraestrutura instalada. As respostas estão demonstradas abaixo.

Como a lei de zoneamento, o Plano Diretor, os incentivos fiscais (20\% para parcela única do IPTU), as normas edilícias e construtivas. (A2)

Não existe assim uma coisa sistematizada nesse sentido, não. Vai trabalhando à medida que vão sendo apresentados os pedidos de licença de construção, a gente vai emitindo os parecer, a Secretaria de Finanças emite o alvará. A gente orienta. A gente tem orientado e tem tido dificuldade com isso. Muitas vezes, você vê aí alguém construiu em cima da calçada. Agora recentemente, o cara vez uma garagem sobre a calçada. A gente notificou, ele disse que não tirava. A gente entrou com um processo judicial. Existe já alguns processos judiciais já com sentenças, já mandando demolir algumas calçadas, algumas coisas na cidade. A gente tenta orientar, tenta acompanhar. (A4)

Hoje o que a prefeitura faz é a questão dos calçamentos, da pavimentação daquela rua, a questão do esgotamento sanitário, a questão de energia pública tem que ser colocar, abastecimento da água. Mas uma das coisas mais importantes que o pessoal quer é a pavimentação das ruas, pois as casas se valorizam. Aí tem as outras questões que é a limpeza pública que a prefeitura faz, conservação do calçamento, é o trabalho que a prefeitura faz. (A5)

Por fim, a entrevista quis averiguar quais as providências que a prefeitura municipal de Currais Novos-RN toma para coibir a prática de construção e uso irregular das edificações.

Exigindo as licenças de construção, as documentações legais do imóvel e a notificação do fiscal de obras. (A2)

Exatamente é isso aí. A gente quando toma conhecimento, notifica. Faz primeiro uma notificação, em seguida se persistir faz um ato de embargo e por último faz uma ação... uma ação na justiça. (A4) 
Toda a construção que será feita em Currais Novos tem que ter a licença de construção. Você quando vai construir algum imóvel em Currais Novos, além das obrigações que você tem com INSS, CREA, aquilo tudo, você tem que chegar na prefeitura e dizer: olha, eu quero uma licença pra construir uma casa na rua tal. A prefeitura vai pedir a documentação todinha - vai pedir CREA, vai pedir isso e vai pedir aquilo - vai ver o imóvel como ele vai construir, tudo direitinho. Aí a prefeitura dá um documento, e ele está liberado para construir o imóvel. (A5)

O autor A2 explica a existência do fiscal de obras, que teria a função precípua de fiscalizar o andamento da construção, bem como, exigir o adequado aproveitamento do solo diante das documentações legais apresentadas. Mas na prática não é o que acontece. A continuação da resposta de $\mathrm{A} 5$ aponta em outra direção completamente diferente.

O que acontece aqui. Muitas vezes, ele começa a construir, nem vai na prefeitura, a prefeitura tem uma fiscalização deficiente, principalmente nos bairros mais distantes, não tem muita gente pra isso. Principalmente nos bairros mais afastados de Currais Novos o pessoal constrói do jeito que eles querem. Inclusive tomando até o arruamento das ruas. Eles constroem na área verde da prefeitura. Existe um bairrozinho aqui que foi construído todo irregular. Foram construindo, invadindo o arruamento, e lá tá uma bagunça. Tem uma rua principal, mas está toda bagunçada, não tem um arruamento, alinhamento. Por que lá atrás o dono vendeu sem fazer um loteamento regular, e não houve fiscalização. (A5)

Como se percebe nos dados apresentados por A5 vê-se que a prefeitura não fiscaliza as construções e edificações no município adequadamente. Essa assertiva entra completamente em contradição com aquilo que foi dito por A4, que expressa que a prefeitura quando toma conhecimento de alguma construção irregular "Faz primeiro uma notificação, em seguida se persistir faz um ato de embargo e por último faz uma ação, uma ação na justiça". Analisando as informações prestadas pelos dois entrevistados, a conclusão só pode recair no sentido de que a prefeitura municipal não tem tomado nenhuma providência para evitar construções irregulares.

\section{CONSIDERAÇÕES FINAIS}

É possível concluir que a destinação da propriedade proporciona o bem-estar e incentiva o atendimento aos direitos humanos, como o reordenamento e requalificação do uso e ocupação do solo, a redução da carência de terras, o combate à especulação imobiliária, investimentos em projetos de moradias e redução dos gastos públicos com implementação de infraestrutura técnica e social. Sendo assim, a propriedade urbana cumpre a sua função social ao ser edificada para fins habitacionais, comerciais, industriais, dentre outros, bem como a preservação de bens ambientais - naturais ou culturais - indicados para tal. O processo de planejamento municipal com arrecadação do IPTU no município de Currais Novos-RN é comprometido por não fazer uso de um documento 
importante como o Plano Diretor, que por sua vez, existe diante a aprovação do Plano Diretor com a lei municipal no 08 de 01/11/2007, porém não é implementado, desta forma geram consequências sociais na cidade, por não promover as ações necessárias para o crescimento social como melhoria na infraestrutura do município.

Constatou-se com esse estudo a importância de se trabalhar com o Plano Diretor junto à sociedade, uma vez que promove o desenvolvimento socioeconômico, sendo a lei municipal que direciona para a aplicação dos instrumentos de promoção social. Pesquisadas as funcionalidades e objetivos dos instrumentos constitucionais, verifica-se que são peças chaves para o desenvolvimento urbano, e não tem apenas a função de arrecadação fiscal, excede os limites de mera fiscalização, fazem com que o proprietário do imóvel urbano cumpra com a obrigação estabelecida no Plano Diretor, e utilize a propriedade urbana de forma a atender sua função social e, assim, mudar a qualidade de vida.

\section{REFERÊNCIAS}

BASSUL, J. R. (2010). Estatuto da Cidade: a construção de uma lei. In: CARVALHO, Celso Santos; ROSSBACH, Ana Claudia (coord.). O Estatuto da cidade: comentado. São Paulo: Ministério das Cidades. p. 71-88.

BRASIL. Constituição da República Federativa do Brasil. Brasília, DF, (1988). Disponível em: <http://www.planalto.gov.br/ccivil_03/constituicao/constitui\%C3\%A7ao.htm>. Acesso em: 25 mar. 2011.

BRASIL. Código Tributário Nacional. Brasília, DF, (1966). Disponível em: <http://www.recei ta.fazenda.gov.br/legislacao/codtributnaci/ctn.htm>. Acesso em: 05 nov. 2011.

BRASIL. (2001). Lei $n^{\circ}$ 10.257, de 10 de julho de 2001 (Estatuto das Cidades). Diário Oficial da República Federativa do Brasil, Poder Executivo, Brasília, DF, 11 jul. Seção 1, p. 1.

CARVALHO, C. S.; ROSSBACH, A. (org.). (2010). O Estatuto da cidade: comentado. São Paulo: Ministério das Cidades.

CURRAIS NOVOS. (2007, 01 NOV). Lei Complementar $n^{\circ}$ 08, de 01 de novembro de 2007 (Plano Diretor Municipal). Poder Executivo, Currais Novos, RN.

FERNANDES, E. (2010). Estatuto da Cidade e a Ordem Jurídico-Urbanística. In: CARVALHO, Celso Santos; ROSSBACH, Anaclaudia (coord.). O Estatuto da cidade: comentado. São Paulo: Ministério das Cidades. p. 55-70.

Instituto Brasileiro de Geografia e estatística. (2016). Perfil... [S.1.: s. n.]. Disponível em: <http://www.cidades.ibge.gov.br/xtras/perfil.php?lang=\&codmun=240310\&search=riogrande-do-norte|currais-novos>. Acesso em: 19 mai. 2016. 
ROCHA, J. M. (2008). Direito tributário. 6a ed. Rio de Janeiro: Editora Ferreira.

SANT'ANA, A. M. de. (2006). Plano Diretor Municipal. São Paulo: Liv. e Ed. Universitária de Direito.

SILVA, J. A. da. (2000). Direito urbanístico brasileiro. 3ạ Ed. São Paulo: Malheiros.

SILVA, C. H. D.da. (2008). Plano Diretor: teoria e prática. São Paulo: Saraiva.

TOMÁS, L. R. (2005). Adequação do plano diretor ao estatuto da cidade: uma proposta em discussão. Uberlândia: Universidade Federal de Uberlândia. 